\title{
Revised methodology for unit wage costs and unit labour costs: explanation and impact
}

\author{
Author Name(s): John Appleton, ONS
}

\begin{abstract}
A revised methodology for whole economy unit labour costs and unit wage costs has been implemented as part of the Q2 2011 Labour Productivity statistical release, published alongside this article on 6 October 2011. These changes are based on recommendations made in a previous article by Turvey (2009). The revised methodology utilises more consistent and robust wage and labour cost estimates for the self-employed. This paper explains the changes undertaken and demonstrates the impact of these changes on the data.
\end{abstract}

\section{Acknowledgements}

1. The author would like to thank Mark Franklin and Ainslie Restieaux for guidance.

\section{Introduction}

Unit wage costs (UWC) measure the cost of wages and salaries incurred in the production of a unit of output. Unit labour costs (ULC) aim to represent the full labour costs, including social security and pension contributions paid by employers etc, incurred in the production of a unit of output.

Although not a direct measure of productivity, since productivity relates the volume of output to the volume of input used to produce that output, an inverse relationship between unit costs and productivity tends to be observed- the higher the growth of a worker's productivity, the lower the growth of labour costs per unit of output and vice versa.

Wages and salaries (W\&S) represent by far the largest component of labour costs. Thus, movements in wages and labour costs are closely correlated over time. However, there can be periods when non-wage labour costs move differently to wages. As a result, unit labour costs are used by the Bank of England among others when analysing the extent of spare capacity in the labour market; as they provide a more comprehensive indicator of the inflationary pressure in the supply side of the economy. For the same reasoning unit labour costs will henceforth take prominence in ONS labour productivity releases. 
Changes described in this article apply only to whole economy estimates. As described later in this article, we plan to extend the revised methodology to sectoral unit labour costs. However this is dependent on data series from Blue Book 2011, publication of which has been postponed. This means that in the accompanying Labour Productivity statistical bulletin, manufacturing unit wage costs have been produced on an unchanged methodology and are therefore not strictly consistent with the whole economy estimates described in this article.

\section{Change in methodology}

One of the difficulties with compiling an accurate measure of the costs associated with labour input within the UK is that there is no direct measure of labour costs in the self-employed sector. Selfemployed people do not remunerate themselves specifically for their labour input, but for a service which also includes capital input embodied in their entrepreneurial effort (Turvey, 2009). The combined returns to their labour and capital inputs are captured by the mixed income series in the National Accounts. The treatment of labour costs for self-employed workers has been the principal reason for this change in methodology.

To obtain a measure of total labour costs, including the self-employed, the previous unit labour cost methodology scaled up compensation of employees (CoE) using the ratio of all persons in employment to all employees. The self-employed constitute the majority of the difference between these two measures in the labour force survey (LFS). To obtain unit labour costs (equation 1) the total labour cost measure was then divided by gross value added (GVA) at basic prices (net of employment subsidies) - which is the recommended measure of output for productivity analysis.

\section{Equation 1: Previous unit labour cost methodology}

previous ULC $=\frac{\text { compensation of employees } \times \frac{\text { LFS employment }}{\text { LFS employees }}}{\text { P. }}$

$$
\text { GVA at Basic Prices }
$$

The previous treatment of labour costs for the self-employed assumed that, on average, the self-employed receive the same absolute compensation for their labour as the employed. This methodology can result in the implied return to self-employed labour being larger than mixed income, an implausible result. Furthermore the remuneration of HM Forces and Government Supported Trainees is accounted for twice, as these groups are included in compensation of employees but not in the LFS measure of employees (for more information see Turvey, 2009).

Unit wage costs were previously derived using an equivalent methodology. A total wage cost measure was derived by scaling wages and salaries to take account of the self-employed, as shown in equation 2.

\section{Equation 2: Previous unit wage cost methodology}

previous UWC $=\frac{\text { wages \& salaries } \times \frac{\text { LFS employment }}{\text { LFS employees }}}{\text { GVA at Basic Prices }}$ 
The revised methodology assumes that the relative returns to each factor (labour and capital) are the same for the self-employed as for the employed. CoE and gross operating surplus (GOS) measure the returns to employed labour and capital respectively, and are used to calculate the factor share ratio (equation 3); demonstrating the proportion of total returns attributed to labour in the employed sector.

\section{Equation 3: Factor share ratio}

factor share ratio $=\frac{\text { compensation of employees }}{\text { compensation of employees }+ \text { gross operating surplus }}$

By applying the factor share ratio to mixed income the implied return to self-employed labour is obtained and combined with CoE creates the total labour cost in the numerator of equation 4 . Unit labour costs are derived by dividing the total labour cost by GVA as previously measured.

\section{Equation 4: Revised unit labour cost methodology}

revised ULC $=\frac{(\text { factor share ratio } \times \text { mixed income })+\text { compensation of employees }}{\text { GVA at basic prices }}$

The revised treatment of the self-employed is conceptually preferable as it incorporates information on the income of the self-employed, which tends to differ from that of employees. The income of the employed and self-employed can follow different trends for many reasons including: movement between the employed and self-employed sectors, exits and entrants from the labour market, and changes in culture, working practices and legislation.

Another advantage of the revised methodology is that the estimate of labour costs is consistent with the income shares of gross domestic product (GDP) in the National Accounts. Since the factor share ratio is bounded between zero and one, the implied return to self-employed labour cannot exceed mixed income as it did previously. Furthermore, the factor share ratio changes through time reflecting changes in the composition of the economy, as the role of capital and labour alter.

Analogous adjustments have been made to the whole economy unit wage cost series in order to make it consistent and comparable with the unit labour cost series. Prima facie, it may seem that the closest equivalent methodology would be to apply an adjustment similar to that between CoE and W\&S for employees, i.e. to assume that the proportional difference between the self-employed labour income and 'wage income' is equal to the proportional difference for the employed. However, the conceptual differences between CoE and W\&S are not transferable to self-employed earnings as non-wage labour costs, such as pension and social security contributions, are made by the individual from mixed income. Consequentially the same factor share ratio is applied to derive the compensation of self-employed labour. The revised methodology for unit wage costs is represented in equation 5. 


\section{Equation 5: Revised unit wage cost methodology}

revised UWC $=\frac{\text { (factor share ratio } \times \text { mixed income })+ \text { wages \& sal aries }}{\text { GVA at basic prices }}$

\section{Impact of the change in methodology}

As a result of the improvements in the treatment of the self-employed within the methodology, revisions will be taken on throughout the whole economy unit labour cost and unit wage cost series. It should be noted that only the measurement of the self-employed labour income has changed. According to the LFS, the self-employed represent 14 percent of UK total employment. Although this represents a significant proportion of the workforce, the trend of unit labour costs is affected more by the labour income of the employed which remains the same under both methodologies.

Figure 1 and figure 2 show the revisions that have taken place to the unit labour cost series as a result of the change in methodology. Across the past 10 years unit labour costs has have shown slower growth than under the previous methodology. The change in the trend growth rate can be attributed to the growth in mixed income as a proportion of the factor share ratio diverging from growth in self-employment as a proportion of total employees. On average the proportion of selfemployed people in the labour force has been increasing across the past decade. As a result the previously measured implied labour income of the self-employed, which assumed that the average labour cost of the self-employed was equal to that of employees, was also increasing. By contrast, the revised implied labour income of the self-employed has shown much slower growth because self-employed earnings have increased as a proportion of total labour income to a lesser extent. 
Figure 1: Impact on unit labour costs

Level
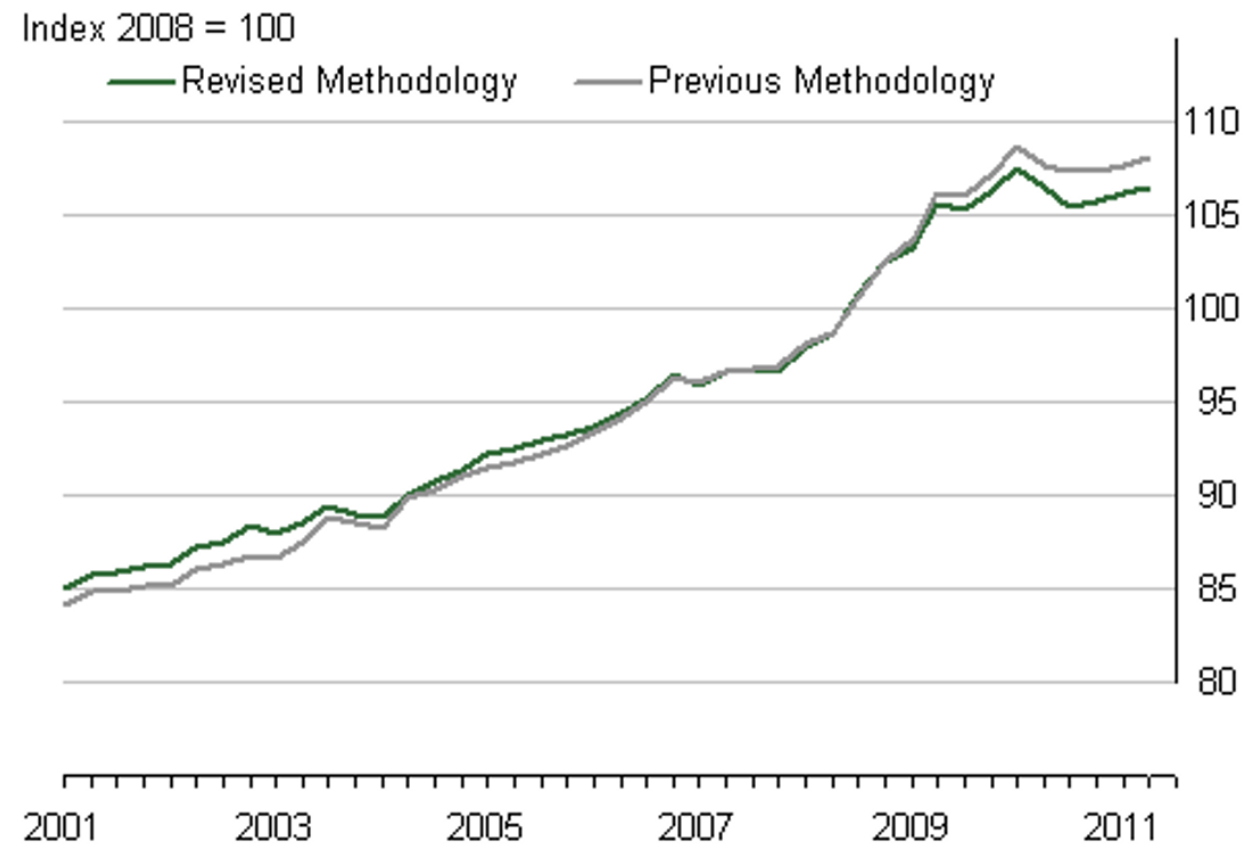

\section{Download chart}

XLS XLS format

$(52.2 \mathrm{~Kb})$

Figure 2: Impact on unit labour cost growth

Change on quarter a year ago

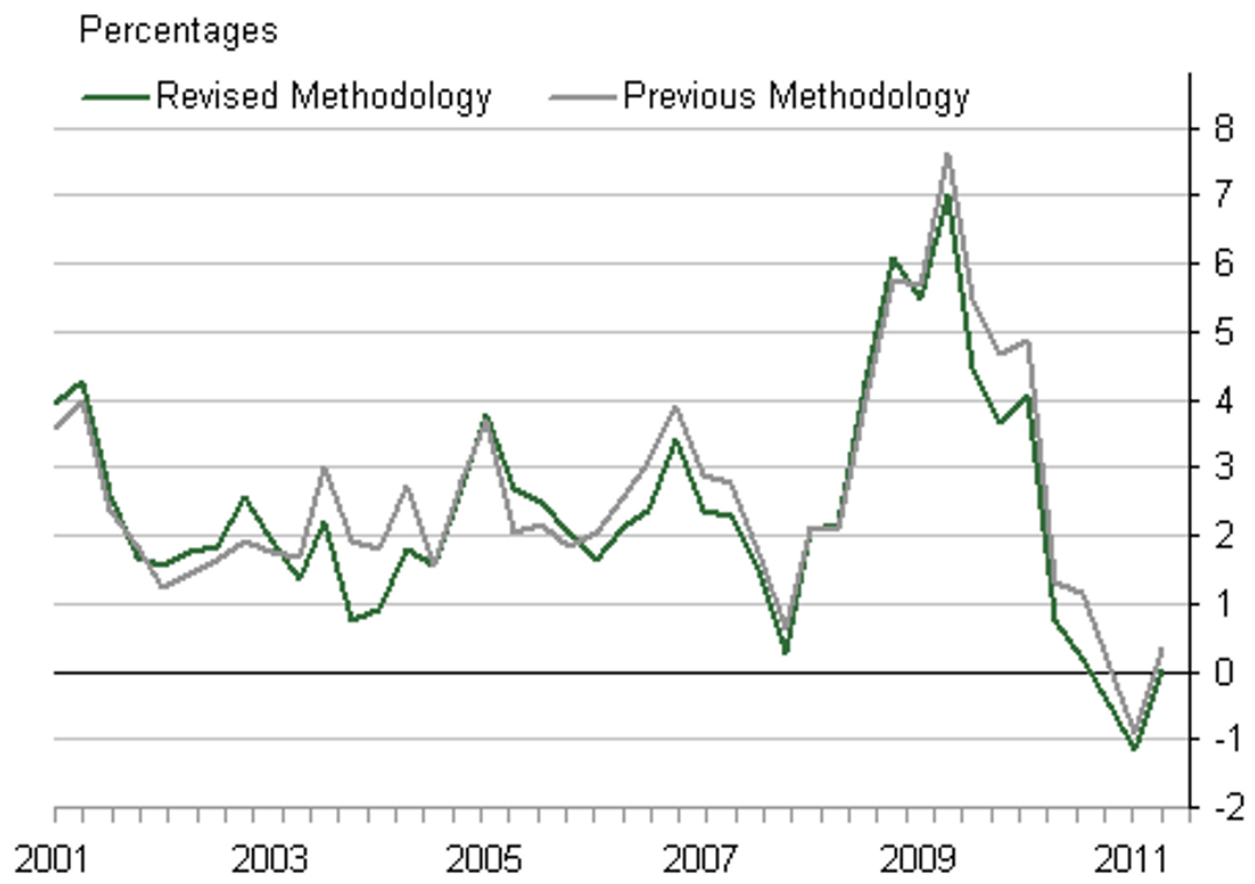




\section{Download chart}

\section{XLS XLS format}

$(52.2 \mathrm{~Kb})$

Figure 2 demonstrates that in the second quarter of 2011, whole economy unit labour costs were are at the same level as the same quarter a year earlier. Under the previous methodology unit labour costs would have been 0.3 per cent higher than the same quarter a year ago. On a quarterly basis, the growth rate of whole economy unit labour costs has been affected by the change in methodology, although the trend is similar to before. Divergence between the growth rates under the two methodologies are a result of the difference in the behaviour of the proportion of selfemployed people and their income as described above. In 2003 and 2004, the increase in the number of self-employed people relative to other employment was large compared to growth in mixed income relative to total income. As a consequence the previous unit labour cost estimates were higher under the previous methodology.

Conceptually, the impact on the trend growth of unit wage costs could be affected more by the revised methodology. This is due to the change from imputing a wage cost for self-employed people to incorporating the implied self-employed labour cost. Furthermore the self-employed labour cost constitutes a greater share of the numerator than in the unit labour cost measure. Otherwise the causes of the revisions are equivalent to those experienced in the unit labour costs results, occurring as a result of developments in the proportion of self-employed people and their remuneration.

Figure 3 and figure 4 demonstrate the impact on unit wage costs. In the second quarter of 2011, whole economy unit wage costs were 0.1 per cent higher than the same quarter a year earlier. Under the previous methodology this was measured as 0.5 per cent. 
Figure 3: Impact on unit wage costs

Level
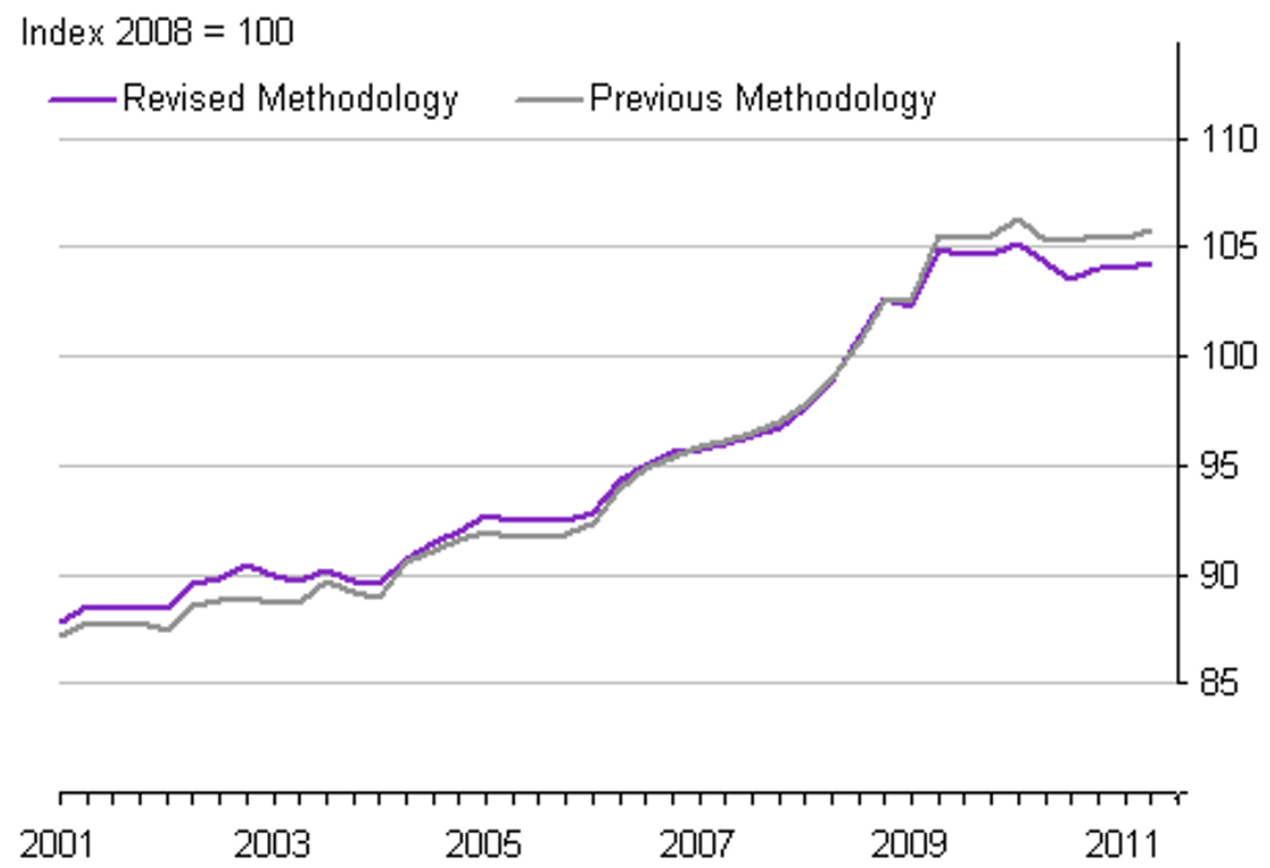

\section{Download chart}

\section{XLS XLS format}

(52.2 Kb)

Figure 4: Impact on unit wage cost growth

Change on quarter a year ago

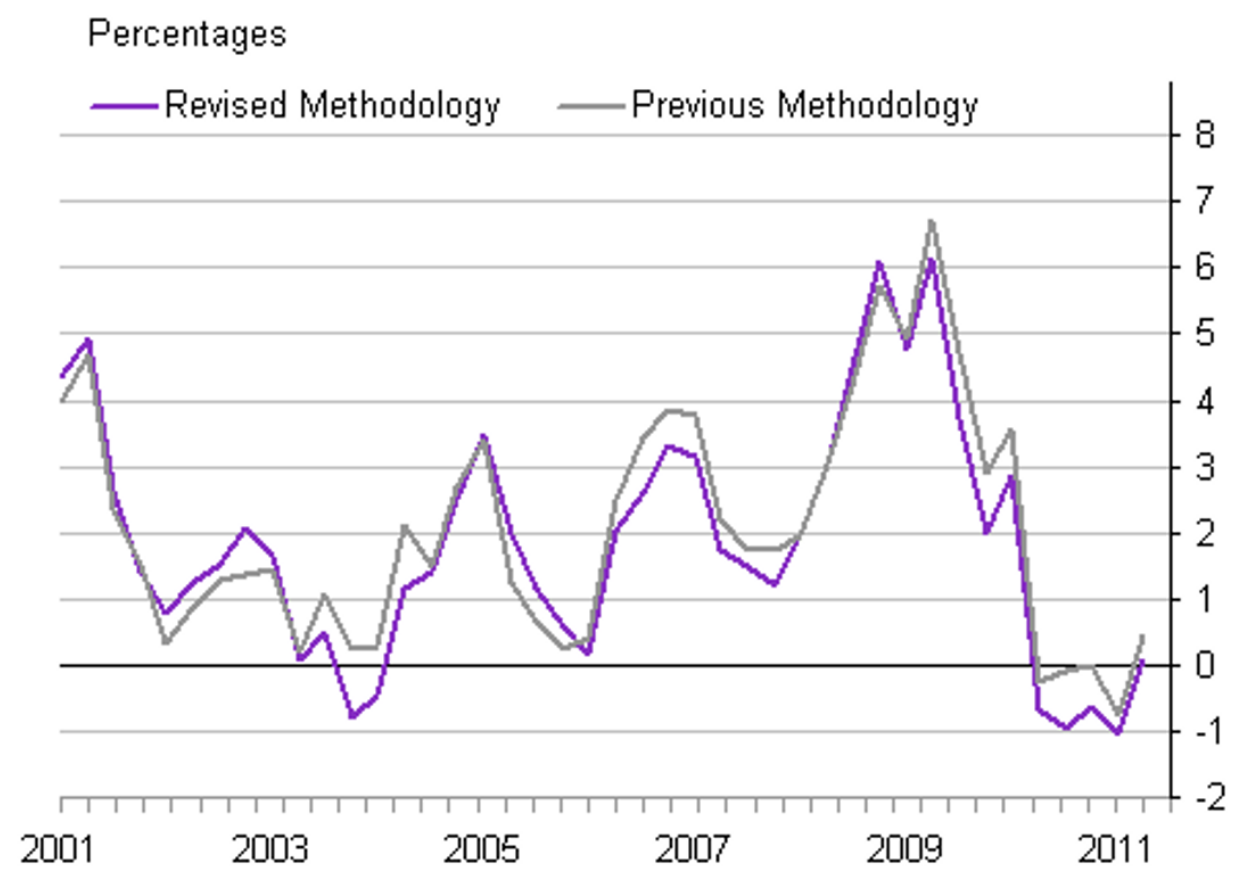




\section{Download chart}

XLS XLS format

$(52.2 \mathrm{~Kb})$

\section{Notes}

1. All data used in the analysis is consistent with the Q2 2011 Labour Productivity statistical bulletin, and the Q2 2011 Quarterly National Accounts.

2. This article only analyses the change in methodology. Further information concerning the sources of revisions between unit labour cost data published on 29 June 2011 and 6 October 2011 are outlined in the Labour Productivity statistical bulletin.

\section{Comparison of unit labour costs and unit wage costs}

Throughout the past decade unit labour costs and unit wage costs using the revised methodologies have followed very similar trends. Figure 5 demonstrates the acceleration of growth in both measures between 2008 Q3 and 2009 Q2. This partly reflects output in the UK economy falling faster than employment, and the associated costs, during the recession. Growth in the series has fallen in the latest quarters although unit labour costs and unit wage costs remain at a higher level than before the recession.

Figure 5: Comparison of unit labour costs and unit wage costs

Change on quarter a year ago

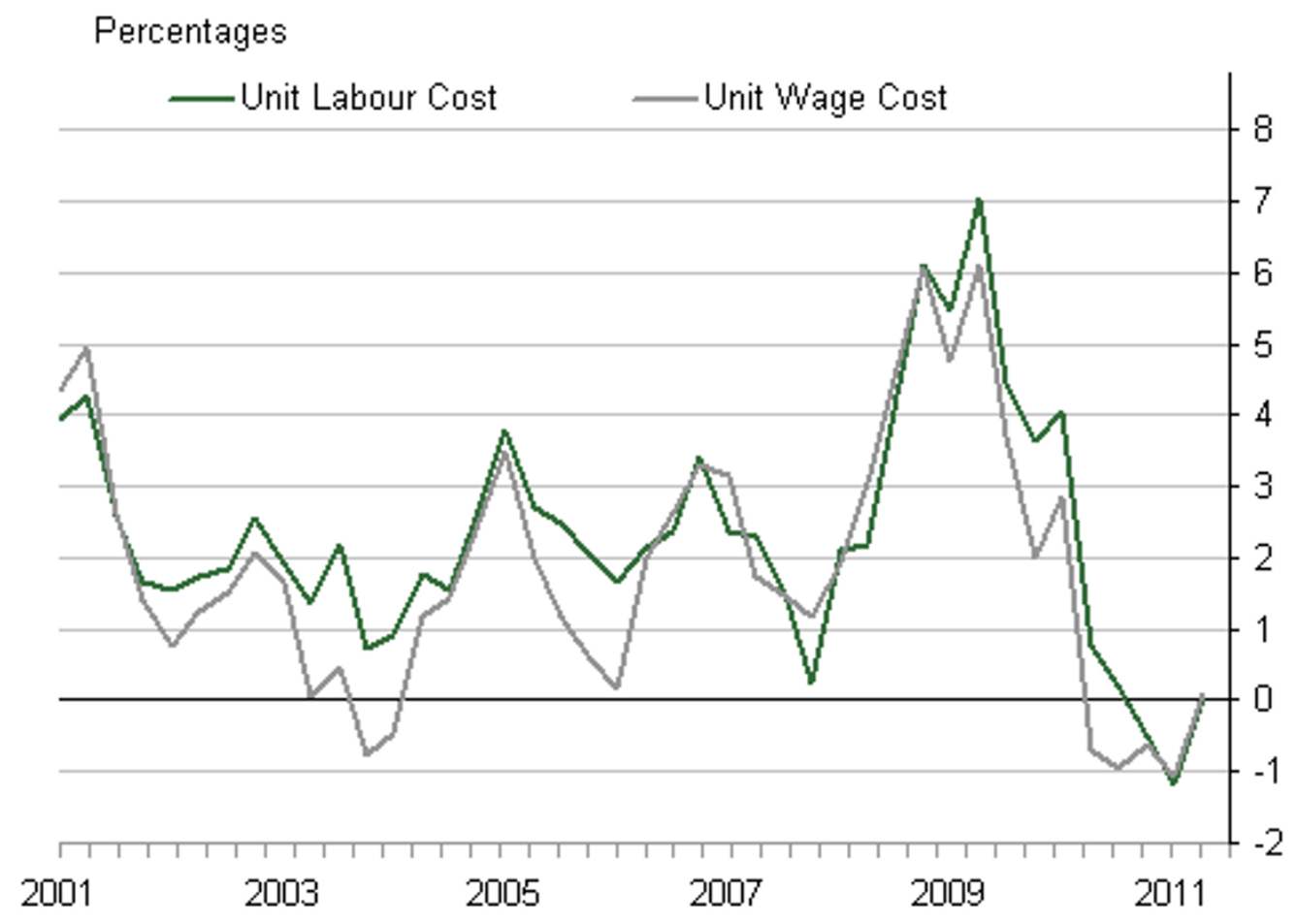




\section{Download chart}

\section{XLS XLS format}

$(52.2 \mathrm{~Kb})$

Growth in the series would be equal if all of the components, such as wages, self-employed income, pension and social security contributions all changed by the same proportion. In the latest quarters this is not the case as growth in wages and salaries has been lower than growth in compensation of employees. This is because wage growth has lagged growth in non-wage labour costs.

\section{Future developments}

It is the intention of ONS to investigate the treatment of the self-employed within its statistics further, and to apply an equivalent methodology to:

1. generate unit labour cost estimates at a more disaggregated level, for example the manufacturing and services sections;

2. account for the remuneration of the self-employed in a consistent manner in other productivity metrics, including: quality adjusted labour input (QALI), volume index of capital services (VICS) and multi-factor productivity (MFP).

\section{References}

1. Bank of England (2011) 'Inflation Report'

2. McKenzie, R and Brackfield, D (2008) 'The OECD System of Unit labour Cost and Related Indicators', OECD Statistics Working Papers, 2008/04, OECD Publishing, also available here

3. Turvey, A (2009) 'Developing a unit labour cost indicator for the UK', Economic and Labour Market Review, Vol 3, No 6, June 2009, pp 51-56 